\title{
Porous Ceramic Filters through 3d Printing
}

\author{
A. Withell, O. Diegel, I. Grupp, S. Reay \\ Centre for Rapid Product Development, Auckland University of Technology, Auckland, New Zealand \\ D. de Beer \\ Technology Transfer \& Innovation, Vaal University of technology, South Africa
}

J. Potgieter

Massey University, School of Engineering and Advanced Technology, Auckland, New Zealand

\begin{abstract}
This paper describes current and on-going work in adapting Z-Corp 3D printers to operate with low-cost ceramic materials. The components produced with these clay-based ceramic powders can be fired to produce strong, complex and lightweight ceramic parts. The final material properties, including the porosity of the parts, can be controlled through the part design and, potentially, through additives to the material that burn out during firing. The paper begins with a brief description of the 3D printing process and how it can be used with clay powders. It then introduces a factorial design experiment initiated to explore the effect of ingredient and parameter variations on the dimensional stability and material properties of green and fired ceramic parts. It then explores the porosity properties of fired ceramic parts for use in filter applications.
\end{abstract}

\section{INTRODUCTION}

Many educational institutions use 3D printers as part of their curricula, to build prototype parts for design and engineering projects. One of the factors that can restrict the use of these printers is the relatively high costs of materials. This often means that students either have to pay for the material costs of 3D printing, or the number of $3 \mathrm{D}$ printed iteration of their designs may be limited, restricting the ability for them to perfect their designs.

This research project was initiated to find a material replacement for the Z-Corp 3D printer that was sufficiently low-cost to allow students at educational institutions to print using additive manufacturing processes without the current cost restriction. As the project developed and began to produce successful parts, it was realised that the low cost ceramic material had potential for a wide range of applications, resulting in the need for further research.

\section{ADDITIVE MANUFACTURING}

Additive Manufacturing is a term referring to a range of layer-upon-layer manufacturing technologies, used for both prototyping and manufacturing purposes. It allows complex components to be manufactured that, in most cases, could not be manufactured using traditional manufacturing techniques.
In contrast to conventional 'subtractive' manufacturing where material is removed from a solid block to create the desired part, 'additive' manufacturing (AM) starts with nothing and builds the part layer by layer until the part is complete (Chua and Leong, 2003). Additive manufacturing is capable of manufacturing complex parts, from a number of different materials, without the need for tooling or machining. AM has few restrictions on the complexity of the parts it can produce, thus giving designers 'complexity for free'.

All additive manufacturing technologies begin with a 3D computer model of the component to be produced. This 3D model is then sliced into thin sections typically ranging from a few microns thick to $0.25 \mathrm{~mm}$ thick depending on the technology by the AM software. The AM machine then makes the part by building each consecutive slice of the model on top of the previous one until the part is complete. The different AM technologies differ in how they build each slice of the component and the material each technology uses.

Although a variety of AM technologies have been used to create ceramic parts (including Selective Laser Sintering (SLS) and Fused Deposition Modeling (FDM), this paper concentrates on the technology developed by Massachusetts Institute of Technology (MIT) that is commonly referred to as 3D Printing. 


\section{$2.13 D$ Printing}

3D Printing is a powder-based AM technology that was developed at MIT around 1993. The technology is one in which a layer of powder is deposited on a build-platform, and liquid binder is applied to the appropriate parts of the layer using an inkjet printer head. Wherever the binder is applied to the powder, the powder solidifies. The build-platform is then lowered, another layer of powder is spread on over the first, and the process is repeated until the part is completed within the powder bed (Figure 1).

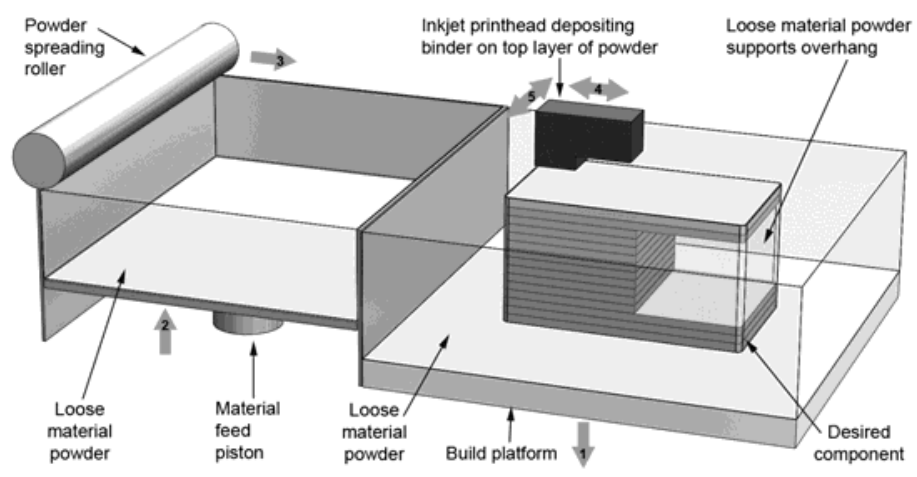

Figure 1: 3D Printing Process Diagram.

After completion, the build-platform is raised and the loose powder that has not had any binder applied to it is brushed away to fully expose the completed "green" part. Options are then available to strengthen components, or make them more flexible by applying additional additives to the part.

Z-Corporation is a 3D Printing licensee that directly addresses the AM market. They use the process to create conceptual models out of starch, plaster and other types of powders. A Z-Corporation system was utilized for this study to explore the potential to convert the system to be used with clay powders.

Clay is a natural mineral aggregate, consisting essentially of hydrous aluminium silicates. It becomes plastic when sufficiently wetted, rigid when dried in the 'green' state, and vitrified when fired to a sufficiently high temperature (Ceramic Tile Institute of America, 2011). A variety of clays are available in powder form, making them ideal to use in powder-based 3D printing systems. In essence, this study explored the potential to deposit the clay material in powder form, wet it with printed liquid to turn it into its plastic form (without the kneading traditionally associated with working with clay), before it dries to its green state, and is subsequently kiln fired to a final vitrified state.

Although there is much literature on the 3D printing of advanced ceramics for bone replacement (Lowmunkong et all, 2009), ceramic scaffolds for biomedical applications (Warnke et all, 2010), and with such advanced materials as Ti3SiC2-based ceramics (Nan et all, 2011), including a seminal paper by Utela, et al, on printing a wide range of powder based materials (Utela et al, 2008), there is little formal literature with respect to the 3D printing of low-cost clay powders.

An examination of the literature available through a variety of open-source forums revealed a large amount of experimental research in the area of 3D printed clay ceramics. The Open 3DP forum, run by the Solheim Rapid Prototyping Laboratory in the Mechanical Engineering Department on the University of Washington (Ganter et al, 2011), and the DIY 3D Printing and Fabrication on Yahoo Forums (Yahoo Forums, 2011), in particular, present a wide range of experimental results and recipes for printing low-cost, clay-based materials.

This literature served as an excellent starting point for this research into developing a low-cost formulation that was suitable for low-cost student printing.

\section{EXPERIMENTAL PROCEDURE}

A range of experiments was conducted in order to examine the effects of multiple variables and their degree of interaction using samples with standardized dimensions. The ceramic material can be influenced at three different levels: the material composition, the printing parameters, and the firing processes.

\subsection{Composition}

An in-powder binder system, based on recipes published at the Open 3DP forum, was chosen as an initial starting point (Table 1). The intent was to trial these as an initial experiment to observe how the ceramic powders behaved in a Z-Corp 310 Plus 3D printer.

Table 1. Original powder recipes from Open 3DP

\begin{tabular}{|l|l|l|}
\hline $\begin{array}{l}\text { Stoneware } \\
\text { Powder }\end{array}$ & $\begin{array}{l}\text { Redart } \\
\text { Terracotta Slip }\end{array}$ & $\begin{array}{l}\text { Xtra Weramic } \\
\text { Ceramite }\end{array}$ \\
\hline $\begin{array}{l}\text { SPS Stoneware } \\
\text { Buff - 1000 units }\end{array}$ & $\begin{array}{l}\text { SPS Redart } \\
\text { Terracotta Slip - } \\
1000 \text { units }\end{array}$ & $\begin{array}{l}\text { SPS Xtra White } \\
\text { Cone 06 - 1000 } \\
\text { units }\end{array}$ \\
\hline $\begin{array}{l}\text { Powdered Sugar - } \\
250 \text { units }\end{array}$ & $\begin{array}{l}\text { Powdered Sugar - } \\
\text { 250 units }\end{array}$ & $\begin{array}{l}\text { Powdered Sugar - } \\
\text { 250 units }\end{array}$ \\
\hline $\begin{array}{l}\text { Maltodextrin - 250 } \\
\text { units }\end{array}$ & $\begin{array}{l}\text { Maltodextrin - 250 } \\
\text { units }\end{array}$ & $\begin{array}{l}\text { Maltodextrin - 250 } \\
\text { units }\end{array}$ \\
\hline
\end{tabular}

The first challenge encountered was that none of the brands/powders listed in the Open 3DP forum were available in New Zealand, so equivalents had to be found. In this project, two different powders were tested, which included a commercially available mid-fire clay powder and a custom-made earthenware powder (Table 2). 
Table 2. Composition of custom-made earthenware powder and binder

\begin{tabular}{|l|l|l|}
\hline \multicolumn{2}{|l|}{ Custom-made Earthenware } & \\
\hline China Clay & $30 \%$ & \multirow{2}{*}{$1000 \mathrm{~g}$} \\
\hline Potash Feldspar & $27 \%$ & \\
\hline Ball Clay & $19 \%$ & \\
\hline Silica & $12 \%$ & \\
\hline Talc & $12 \%$ & $250 \mathrm{~g}$ \\
\hline Powdered Sugar & & $250 \mathrm{~g}$ \\
\hline Maltodextrin & & \\
\hline
\end{tabular}

In contrast to the proprietary Z-Corp materials, in which the liquid binder (table 3) consolidates the powder, the above recipes use maltodextrin and sugar in the powder material to act as an adhesive which binds the powder when activated by the selectively deposited printing liquid. The alcoholbased printing fluid dissolves the hygroscopic maltodextrin and sugar on contact, forming a matrix in which the clay particles are bound. During printing and curing the volatile printing liquid evaporates leaving little residue. This system is not specific to clay powders and can also be used in combination with metals such as titanium (Utela et al, 2008, Wiria, 2003).

Table 3. Original binder recipe from Open 3DP

\begin{tabular}{|l|l|l|l|}
\hline \multicolumn{3}{|l|}{ XF1 Recipe } & XB1 Recipe \\
\hline $\begin{array}{l}\text { 91\% pure } \\
\text { Isopropyl }\end{array}$ & $23 \%$ & $\begin{array}{l}\text { Denatured } \\
\text { ethanol }\end{array}$ & $750 \mathrm{ml}$ \\
\hline $\begin{array}{l}\text { Distilled } \\
\text { Water }\end{array}$ & $77 \%$ & $\begin{array}{l}\text { Distilled } \\
\text { Water }\end{array}$ & $1500 \mathrm{ml}$ \\
\hline $\begin{array}{l}\text { Food } \\
\text { Colouring }\end{array}$ & $\begin{array}{l}\text { a few } \\
\text { drops }\end{array}$ & $\begin{array}{l}\text { Food } \\
\text { Colouring }\end{array}$ & a few drops \\
\hline
\end{tabular}

The HP10 cartridge, which is the one used by the Z-Corp 310 Plus 3D printer needs a surface tension of 45 dynes/cm, and a viscosity of 1.35 cps (Utela et al, 2008 ). Water is the main component of the binder but, as water has a surface tension of 72 dynes/cm this surface tension needs to be reduced in order to function with the print heads. The addition of isopropyl alcohol (IPA) as a surfactant reduces the surface tension to a level suitable for the print head. The addition of food colouring was optional and was used to make it easier to see the object being printed. As the colour is an organic based material, it burns out during firing.

\subsection{D Printing Parameters}

The ZPrinter 310 Plus (Z-Corp) allows adjustment to the following settings: saturation level (binder/volume ratio) and layer thickness. The porosity and stability of the green parts is influenced by these parameters. The amount of rest time required before a part can be removed from the build platform depends on the curing time, and therefore on the saturation settings. In addition, the volatility of printing liquid plays an important role. The saturation levels can be adjusted separately for the outer shell and inner core of an individual part. The ratio between the printing liquid and the material/binder mix influences the degree of consolidation during printing. The layer thickness not only determines the final resolution of a part, but also affects the required infiltration depth of the printing liquid.

\subsection{Firing Parameters}

Firing transforms printed green parts into vitrified ceramics. A debinding of the part takes place as the binder burns out during the firing process and leaves little residue. Critical parameters in the firing process are the heating rate, maximum temperature and holding time.

A fast a heating rate can cause cracks and an incomplete or inhomogeneous sintering of the clay particles. The maximum temperature and holding time influence material strength, shrinkage and distortion. After firing at low temperatures the material is, in general, more fragile and porous while vitrifying at high temperatures adds rigidity.

\section{RESULTS}

The objective of this research was to create strong ceramic parts. The green parts had to provide enough strength to remove them from the 3D printer, and to depowder. In addition, the dimensional accuracy is an important attribute with respect to the usability of a component produced using this process. While homogenous shrinkage can be compensated for in the CAD model, the unpredictable distortion of a part may render it useless for the majority of applications. To analyse the overall suitability of parts created with different parameter combinations their external dimensions were measured and compressive strength tests were performed using a Hounsfield compression tester.

\subsection{Effects of Composition}

Two different clay powders and two printing fluids were used to create 4 series covering all possible combinations based on the recipes provided by Open 3DP. It was possible to achieve strong ceramic parts using each combination. The main difference observed was in the saturation required for the shell and core of a part. As IPA is more volatile than ethanol, a higher saturation level was necessary to solidify the powder into the green parts. In addition, the custom-made powder was observed to produce parts with greater strength than the commercially available powder. 


\subsection{Effects of 3D Printing Parameters}

The saturation settings are the most important factor that influences the strength of green and fired parts, but also influences the degree of shrinkage and distortion of a part. A high saturation resulted in the creation of strong green parts but significant inhomogeneous shrinkage occurred during the printing process. The use of a high concentration of printing fluid resulted in an immediate interaction with the binder which led to a decrease in part volume. The resulting "gaps" were subsequently filled with a new layer of powder, resulting in the formation of a higher packing density and structural cohesion. As the liquid drained to the bottom of a part (due to gravity), this effect was intensified resulting in a tapered shape of the final part. A smaller amount of liquid affected the structural integrity of the green part, but resulted in high porosity and good dimensional accuracy (Figure 2).

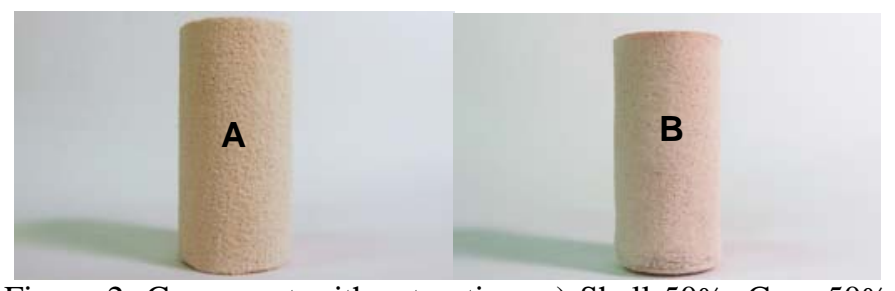

Figure 2: Green part with saturation: a) Shell 50\%, Core 50\% b) Shell $100 \%$, Core $100 \%$

Increasing the layer thickness required a higher saturation to ensure complete infiltration and cohesion between layers.

After firing at high temperatures the level of saturation had an inverse relationship to the strength of a part. Samples with lower saturation tend to result in relatively dense parts, but parts were observed to demonstrate a compressive strength comparable to concrete.

\subsection{Effects of Firing Parameters}

The firing temperature affected the part properties with respect to the degree of shrinkage and compressive strength. Bisque firing at low temperatures resulted in foam-like, extremely brittle parts without structural cohesion. At this stage, most of the binder had already burned out while the clay particles had not sintered together properly. Parts printed with a higher saturation level were slightly stronger, most likely due to the higher packing density. With an increase in temperature, greater vitrification took place transforming the powder compound into a ceramic part (figure 3). The vitrification causes significant shrinkage which exceeds the shrinkage occurring when firing slipcast parts (figure 4). The shrinkage was sometimes inconsistent between the top and bottom of the part. This is one of the factors resulting in inhomogeneous shrinkage that will be addressed in the future.

Holding time, or how long a part is kept at maximum temperature, was another parameter investigated in this project. Longer holding times were observed to allow the particles to rearrange more thoroughly. Consequently, they were able to sinter into a stronger part.

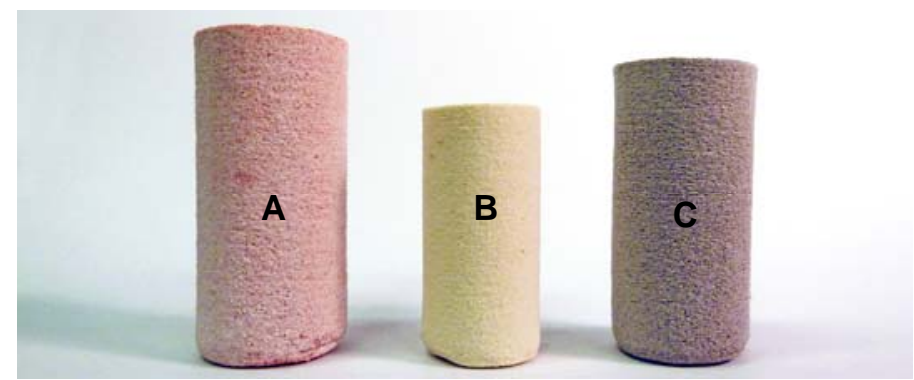

Figure 3: Effects of firing: a) green part, b) fired at $1200^{\circ} \mathrm{C}, \mathrm{c}$ ) fired at $600{ }^{\circ} \mathrm{C}$

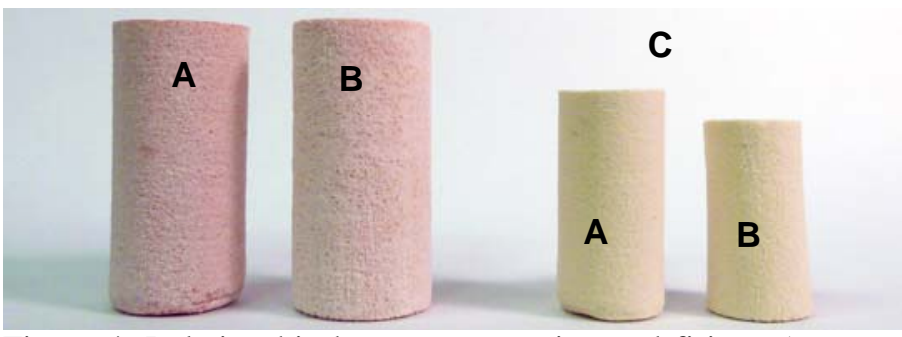

Figure 4: Relationship between saturation and firing: a) green part (saturation: Shell 100\%, Core 100\% ), b) green part (saturation: Shell 50\%, Core 50\%), c) the same parts after firing at $1200^{\circ} \mathrm{C}$

\section{POROUS FILTER APPLICATION}

A series of ceramic filters were produced in order to test whether variations on printing parameters had an effect on their porosity. These filters consisted of discs which were designed in CAD to measure $100 \mathrm{~mm}$ diameter $\mathrm{x} 5 \mathrm{~mm}$ thick (figure 5). They were produced with a number of different binder saturation levels, and ingredient mixes to determine the effect of these parameters on porosity.

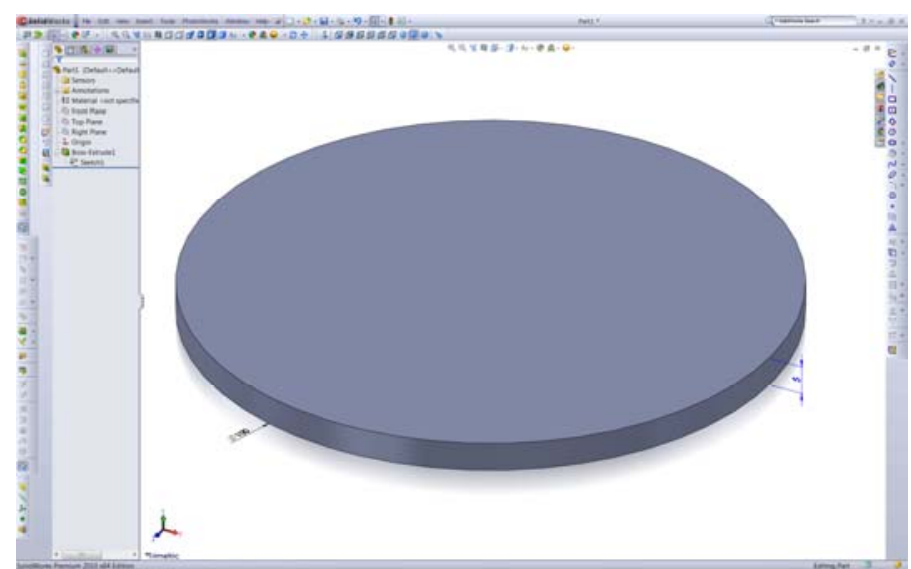

Figure 5: Simple 100mm diameter x 5mm thick filter 
In this section we present some preliminary results in which the porosity of the filters is estimated from an analysis of the microscopy pictures of the filters. Close up pictures of the filters were taken with an Olympus BX60M microscope camera and the pictures were analyzed with ImageJ.

A comparison was made between the surface area of solid material and the pores in the material. For each sample, at least 8 pictures were taken across the surface of the filter, and the porosity for each picture was estimated using the ImageJ software, and the values for each filter averaged.

It should be noted that, for this particular paper, there was not enough time to undertake strength testing on the filters in order to correlate changes in strength to corresponding changes in porosity. This work will be the focus of a future paper which will present the complete factorial design experiment and tabulate results for a complete comparison.

As can be seen from the results below (Table 4 and figures 6, 7, 8 and 9), a variation in the saturation levels ranging from $50 \%$ to $100 \%$ produces a difference in porosity of around 8\%. A change in the proportions of clay powder, sugar and maltodextrin produces variations in porosity of around $10 \%$.

Table 4. Effect of print parameters on porosity

\begin{tabular}{|c|c|c|c|c|c|c|}
\hline 哥 & 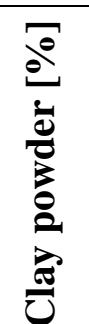 & $\begin{array}{l}\bar{\partial} \\
\overline{0} \\
\overline{0} \\
\overline{0}\end{array}$ & 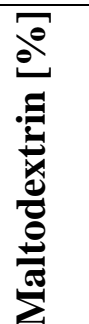 & $\frac{\sqrt[0]{0}}{\text { De }}$ & 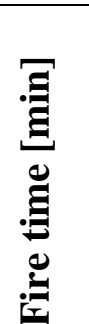 & 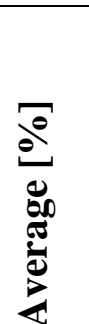 \\
\hline 4 & \begin{tabular}{|l|l}
66.7 \\
\end{tabular} & 16.7 & 16.7 & 100 & 360 & 28.4 \\
\hline 5 & 66.7 & 16.7 & 16.7 & 75 & 360 & 29.2 \\
\hline 6 & 66.7 & 16.7 & 16.7 & 50 & 360 & 22.1 \\
\hline 17 & 66.7 & 0 & 33.3 & 75 & 360 & 31.4 \\
\hline 23 & 50 & 25 & 25 & 75 & 360 & 21.0 \\
\hline
\end{tabular}

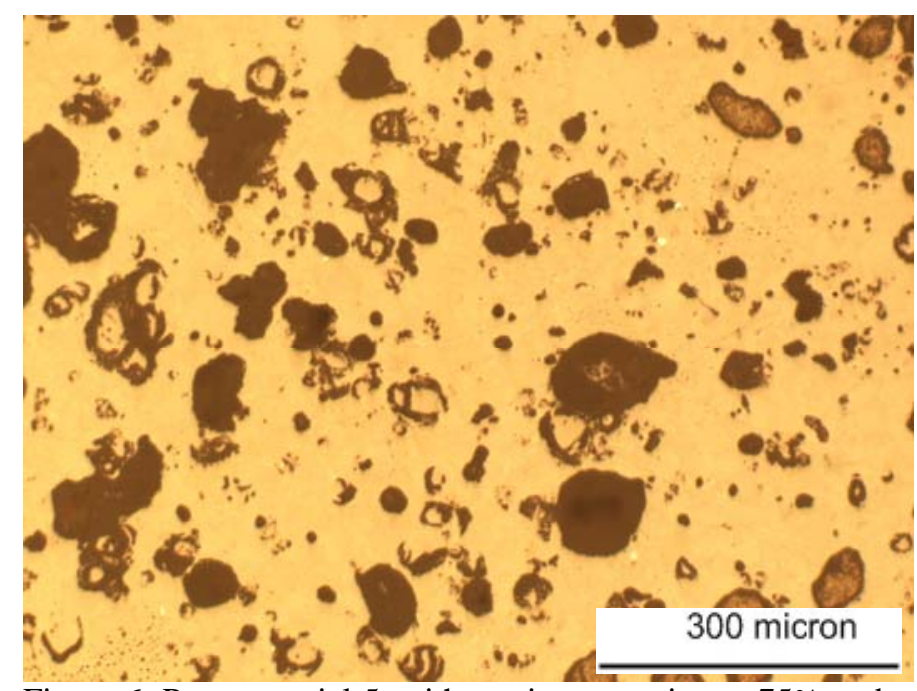

Figure 6: Pores on trial 5, with a print saturation at $75 \%$ and a $29.2 \%$ porosity.

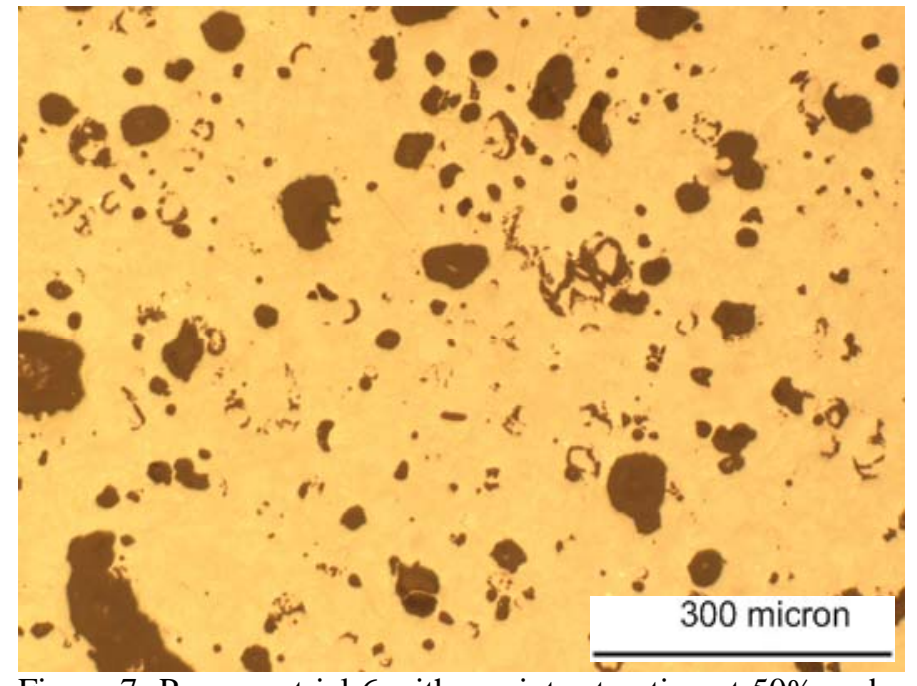

Figure 7: Pores on trial 6 with a print saturation at $50 \%$ and a $22.1 \%$ porosity.

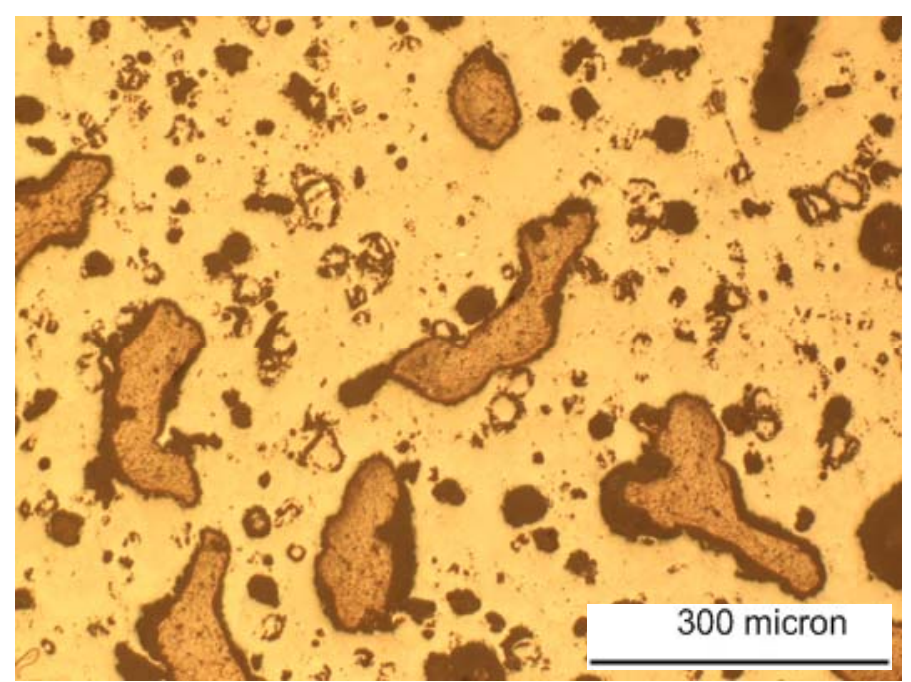

Figure 8: Pores on trial 17 with $66.7 \%$ clay, no sugar, 33.3\% maltodextrin, a print saturation at $75 \%$ and a $31.4 \%$ porosity.

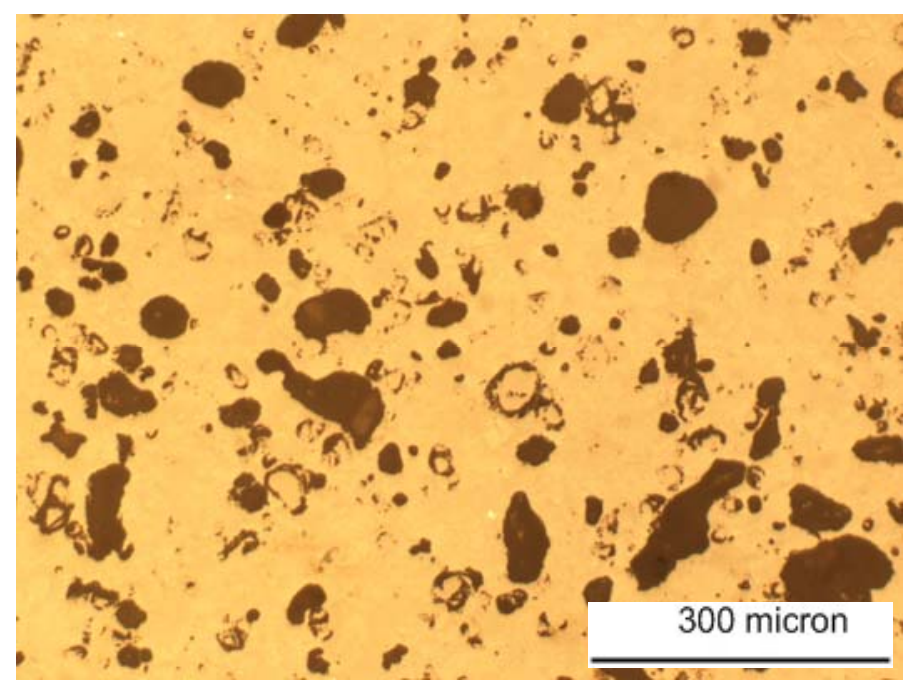

Figure 9: Pores on trial 23 with 50\% clay, 25\% sugar, 25\% maltodextrin, a print saturation at $75 \%$ and a $21.0 \%$ porosity.

\section{CONCLUSIONS}

This paper has described current and on-going work in adapting Z-Corp 3D printers to operate with low-cost ceramic materials. The components produced with these clay-based ceramic powders can be fired to produce strong ceramic parts 
at very low cost (around US\$1/Kg). The paper describes the effect of the various parameters and how they influence the quality of the finished part.

The paper also describes some preliminary experimental work on producing porous ceramic filters in which the porosity can be controlled by varying the parameters such as print saturation, and material composition.

Future work on this project includes analysing the varying porosity and collating it with the effect of parameter variations on strength, hardness, etc. Experimental work will also be done on testing filters in which the geometric structure of the filter is changed to include channels and other features to aid in the filtration of specific contaminants.

\section{REFERENCES}

Ceramic Tile Institute of America, Glossary of Terms, http://www.ctioa.org/index.cfm?pi=GL\&gaction=list\&grp= C, Accessed March, 2011

Chua, C.K., Leong, K.F., Rapid Prototyping: Principles and Applications. (2nd ed). World Scientific Publishing Co, Singapore, 2003

Lowmunkong, R, Sohmura, T., Suzuki, Y., Matsuya, S., Fabrication of freeform bone-filling calcium phosphate ceramics by gypsum 3D printing method, Journal of Biomedical Materials Research Part B: Applied Biomaterials, Volume 90B, Issue 2, pages 531-539, August 2009

Ganter, M., et al., open 3D printing forum, http://open3dp.me.washington.edu/, 03/2011

Nan, B., Yin, X., Zhang, L., Cheng, L., Three-Dimensional Printing of Ti3SiC2-Based Ceramics, Journal of the American Ceramic Society, Article published online: Feb 2011

Utela, B., Storti, D., Anderson, R., Ganter, M., A review of process development steps for new material systems in three dimensional printing (3DP), Journal of Manufacturing Processes 10 (2008) 96 -104

Warnke, P.H., Seitz, H., Warnke, F., Becker, S.T., Sivananthan, S., Sherry, E., Liu, Q., Wiltfang, J., Douglas, T., Ceramic scaffolds produced by computer-assisted 3D printing and sintering: Characterization and biocompatibility investigations, Journal of Biomedical Materials Research, Volume 93B, Issue 1, pages 212-217, April 2010

Wiria FE, et al. Printing of Titanium implant prototype. J. Mater. Design (2010). Ink-jet printing of highly loaded particulate suspensions. MRS Bulletin 2003;28(11):815 ${ }^{\perp} 8$.

Yahoo Forums, DIY 3D Printing and Fabrication, http://tech.groups.yahoo.com/group/diy_3d_printing_and_f abrication/, March, 2011 